Title: Justice in the Distribution of Knowledge

Authors: Faik Kurtulmuş and Gürol Irzık

Affiliations: Department of Philosophy, Sabanc1 University

Short title: Justice in the Distribution of Knowledge

Corresponding author: Faik Kurtulmus, afaikkurtulmus@sabanciuniv.edu

Received: $5 / 28 / 2014$

Revised: 3/2/2015, 18/8/2015, 13/11/2015

Accepted: 15/11/2015

\begin{abstract}
In this article we develop an account of justice in the distribution of knowledge. We first argue that knowledge is a fundamental interest that grounds claims of justice due to its role in individuals' deliberations about the common good, their personal good and the pursuit thereof. Second, we identify the epistemic basic structure of a society, namely, the institutions that determine individuals' opportunities for acquiring knowledge and discuss what justice requires of them. Our main contention is that a systematic lack of opportunity to acquire knowledge one needs as an individual and a citizen because of the way the epistemic basic structure of her society is organized is an injustice. Finally, we discuss how our account relates to John Rawls's influential theory of justice.
\end{abstract}

Keywords: distribution of knowledge, science, values, democracy, John Rawls 


\section{JUSTICE IN THE DISTRIBUTION OF KNOWLEDGE}

\section{INTRODUCTION}

Current theories of distributive justice focus on institutions that distribute goods such as income, wealth, liberties and opportunities and do not address the organization of institutions that are primarily concerned with the production and dissemination of knowledge. Given that knowledge is an essential good for human flourishing, democratic rule and just legislation, we argue that the distribution of certain kinds of knowledge deserves to be treated as a matter of justice in its own right and that the institutions primarily responsible for the distribution of knowledge are subjects of justice. To this end we develop a normative theoretical framework whose central element is what we call the epistemic basic structure of a society. ${ }^{1}$ By this we mean the institutions that have a crucial role in the distribution of knowledge, that is, in the production and dissemination of knowledge, and in ensuring that people have the capability to assimilate what is disseminated by providing them with the necessary educational background and intellectual skills. ${ }^{2}$ The epistemic basic structure includes institutions of science and education, media, libraries open to the public, and those government agencies and offices that carry out research or publish basic statistics. Our central claim is that justice requires that people have the opportunity to acquire knowledge about matters that they have an objective interest in as individuals and citizens, and this in turn requires that the epistemic basic structure of their societies produce and disseminate such knowledge and provide them with the capabilities they need for assimilating it. Accordingly, a systematic lack of opportunity to acquire knowledge one needs as an individual and a citizen to reason about the common good, her individual good and pursuit thereof because of the way the epistemic basic structure of her society is organized is an injustice.

Before we proceed, some terminological clarifications are needed.

\footnotetext{
${ }^{1}$ Our use of this notion is inspired by but not identical with Rawls's idea of the basic structure of a society see Rawls (1999: 6-10).

${ }^{2}$ Throughout this article when we speak of the distribution of knowledge, we refer to the processes of production and dissemination of knowledge, and ensuring individual capability to assimilate it.
} 
Throughout this article, by the term 'knowledge' we shall mean what Goldman has called weak knowledge, 'which is simply true belief (Goldman 1999: 24). Goldman distinguishes weak knowledge from strong knowledge which is true belief plus further conditions such as justification, warrant and conditions that would rule out Gettier cases. In this article we are concerned with weak knowledge rather than strong knowledge for three reasons. First, we wish to sidestep debates about what conditions other than true belief is necessary for strong knowledge. Second, on most accounts of the conditions to be added to true belief to have knowledge in the strong sense, there is an element of individual cognitive performance, which is the responsibility of the epistemic agent, and not down to the institutions that we shall be concerned with. Third, our arguments for treating the distribution of knowledge to be a matter of justice apply in the first instance to weak knowledge, and their extension to strong knowledge is not straightforward.

A further clarification is needed. Our talk of distribution of knowledge should be read as shorthand for distribution of the opportunity to acquire knowledge. This qualification is needed for two reasons. First, there is no guaranteed way of acquiring true beliefs. Our most reliable way of acquiring true beliefs is through well-conducted research, and yet it is not a guarantee for acquiring knowledge; it is merely our best bet. Second, what justice requires is not that people know all the facts that they have an interest in, but that they can come to find out about them, or rather the results of wellconducted research on them. Since the expression 'the distribution of opportunity to acquire the results of well-conducted research which is highly likely to be true' is too cumbersome, we will use the phrase 'the distribution of knowledge'.

Here is how we shall proceed. We first identify the various reasons why knowledge is a fundamental interest (section 2). We then identify the processes and institutions that have a key role in determining individuals' opportunities for acquiring knowledge and outline what justice requires of them (sections 3 and 4). Finally, we discuss how the framework we develop in this paper can be incorporated into John Rawls's influential theory of justice (section 5). 


\section{THE OBJECTIVE INTEREST IN KNOWLEDGE}

We have a fundamental interest in certain kinds of knowledge as individuals and as citizens of liberal democracies. First, we need knowledge to deliberate about how we should live and the ends we should pursue, that is, on questions regarding the good life. Our deliberation about how we ought to live depends on having knowledge about various aspects of the world and different conceptions of the good life as well as possessing the conceptual resources and intellectual skills to carry out such deliberation. Second, we need knowledge to successfully pursue our ends. In addition to various resources and liberties, we need to have a more or less accurate conception of the world that will enable us to identify effective ways to pursue our ends. While the pursuit of some of our ends will require local and trivial knowledge that is easy to come by, the pursuit of other ends and the carrying out of long-term plans will require knowledge that can only be obtained through epistemic institutions. ${ }^{3}$

We also need knowledge as citizens to ensure a well-functioning democracy. Democratic rule requires not only that citizens be able to express themselves, but also that they be sufficiently informed about issues that bear on the common good and have the opportunity to deliberate about them. Deliberating about the common good requires having knowledge about the needs and perspectives of other citizens, about how our society is performing with regard to issues that bear on the common good and which policies can further it. In the absence of a well-informed democratic process, we can expect neither sound policies nor legislation that treats the viewpoints and needs of all citizens with equal respect and concern.

As citizens of authoritarian regimes know too well, an uninformed citizenry kept in the dark about the actions of its government is a recipe for tyranny. Democracy requires holding the government accountable to the citizens, which in turn requires a free press that can inform them of the actions of their government so that they can respond to them. The knowledge provided by a well functioning free press is one of the most effective means

\footnotetext{
${ }^{3}$ In addition to the instrumental value of knowledge in enabling us to lead a good life, many theorists of welfare would claim that knowledge is also intrinsically valuable and a component of the good life (Finnis 2011: 59-80). While we are sympathetic to this claim, our argument in this paper does not rest on it and is compatible with liberal neutrality. For a discussion of liberal neutrality see Kymlicka (1989), Rawls (1996).
} 
of fighting against repression and corruption.

A further connection between democracy and knowledge emerges when we reflect on the Baconian idea that knowledge is power. Individuals' and social groups' chances of democratic participation and their ability to influence the political process depend not only on the financial and other resources they have, but also on the knowledge that they possess. People who have a more accurate conception of their social world, such as the existing networks of power, the workings of different political institutions, the possible results of certain policies and the current state of public opinion, will be in a better position to propose and implement policies that further their goals than those who lack such a conception. Therefore, inequalities in the distribution of knowledge can produce significant inequalities in political power that can undermine a democracy. Furthermore, well-informed people will be less vulnerable to misleading propaganda.

In addition to being essential for democracy, certain kinds of knowledge are necessary for just legislation and its effective implementation. Just legislation is more likely if citizens are well informed and have had the opportunity to reflect on the common good. Furthermore, the successful realization of the ends adopted by society will require that the various institutions and professional bodies assigned with the task of realizing them have the requisite knowledge. Knowledge, therefore, contributes to just legislation by improving deliberations about the common good and ensuring that it is pursued effectively by the relevant institutions.

In light of our survey of the interest in knowledge, we can offer a more nuanced understanding of justice in the distribution of knowledge. Lack of knowledge due to an unjust epistemic basic structure is both an injustice in itself and facilitates other injustices. An unjust epistemic basic structure is a source of injustice in itself because it denies some individuals the means to deliberate about and pursue their own good. An unjust epistemic basic structure also contributes to other injustices. First, it undermines political equality by providing some with greater chance to influence the political process. Second, it makes just legislation and effective policy less likely, because a society with a badly functioning epistemic basic structure will not have reliable information about the interests and conditions of its citizens relevant to its legislation and its policies. To cite one example, Marilyn Waring has forcefully argued that the United Nations System of National Accounts, which is used in the calculation of a country's GDP and guides 
economic policy, excludes many economic activities typically engaged in by women, thereby making their labour invisible and resulting in policies that fail to take their interests into account (Waring 1988). Third, lack of knowledge and research can hinder the effective exercise and realization of many rights citizens have. Lack of knowledge, no doubt, can diminish people's health, which will in turn narrow the range of opportunities open to them. Moreover, this lack can disadvantage particular groups, thereby raising questions of distributive justice. For example, there is "a lack of a concerted research and development effort to improve diagnostic testing methods or drugs and vaccine" for some tropical and parasitic diseases that inflict especially the poor and people of African descent in the U.S.A. (Hotez 2009). As these examples suggest, all of these harms caused by an unjust epistemic basic structure have a distributive element and give rise to considerations of fairness.

A badly functioning epistemic basic structure also causes harms that impact everyone. For one thing, it can cause not only unjust but also bad policy choices. If, for instance, pharmaceutical research is conducted in ways that are unreliable, then everyone will suffer as a result. For another, if the population at large is ignorant of the grounds for sound policies, there will be a trade-off between them and democratic legitimacy since the population will be ignorant of the reasons that justify a given policy. Finally, a badly functioning epistemic basic structure undermines government accountability and makes abuse of political power more likely.

Broadly speaking, then, the epistemic basic structure of a society has two roles relevant to justice. Its first role is to provide individuals in that society with the opportunity to acquire knowledge they have an interest in. Its second role is to enable institutions within a society, such as the health care system, bodies making economic policies, or the criminal justice system, to carry out their tasks by producing and disseminating the knowledge they need to carry out their specialized tasks. While a full treatment of the organization of the epistemic basic structure in a just society has to address both aspects of its organization, in this paper we focus for the most part on its first role. ${ }^{4}$

\footnotetext{
${ }^{4}$ Nevertheless, it's worth pointing out that the two roles of the epistemic basic structure are interrelated for what individuals need to know to pursue their ends depends on the distribution of labour in a society. If there are people specialized in carrying out a certain
} 
The interest in knowledge has not been neglected by liberal theories of justice. In fact, freedom of expression, which is a sine qua non of liberal democracies, has often been defended by its role in facilitating both individual and collective deliberation and enabling people to acquire knowledge. ${ }^{5}$ However, freedom of expression is not enough, by itself, to ensure that citizens are informed about matters of common concern to all, or about matters concerning their individual well-being. Citizens of societies with stringent protection of freedom of expression such as the U.S.A. might remain ignorant about issues that bear significantly on their common good and individual well-being when the epistemic basic structure of their societies is not functioning properly.

A cursory glance at the research on public informedness on crucial issues such as global warming, distribution of income and wealth, and the welfare services offered by the state confirms this worry. For example, despite the fact that the U.S. National Research Council's 2010 report, which outlines the scientific consensus on the issue of climate change, states clearly that "climate change is occurring, is caused largely by human activities, and poses significant risks for - and in many cases is already affecting - a broad range of human and natural systems" (National Research Council 2010: 2), only $34 \%$ of the U.S. population believes that the Earth's climate is being affected by human-induced global warming (Pew Research Center 2010). Similarly, Americans "vastly underestimate the actual level of wealth inequality in the United States, believing that the wealthiest quintile held about $59 \%$ of the wealth when the actual number is closer to $84 \%$." (Norton and Ariely 2011). Finally, 53.3\% of people who have received student loans, which are provided by banks but subsidized by the federal government, report that they have not used any government social programs (Mettler 2010). Obviously, the public's being misinformed about these rudimentary

task for others, then people will not necessarily need to know how to carry out that task themselves, but will need knowledge to identify people who are competent. Naturally, the distribution of labour a society should adopt and inter alia the distribution of knowledge needed depends on many factors such as efficiency, cost etc. While we touch upon some aspects of these issues here, we plan to offer a detailed discussion in a separate paper.

${ }^{5}$ Arguments similar to ours have often been used to defend freedom of expression as a necessary means for attaining knowledge. The connection between public deliberation and democratic rule is central to Meiklejohn's defence of freedom of expression (Meiklejohn 1948). Deliberation about different conceptions of the individual good and how best to pursue them is central to Cohen's defence of freedom of expression, and of course Mill's classical defence as well (Cohen 1993, Mill 1989). 
and uncontroversial but nonetheless highly relevant facts will seriously affect their political choices and the justice of resulting legislation.

These shortcomings of freedom of expression to ensure, by itself, that citizens are well informed are not surprising. As social epistemologists have emphasized, just as how we fare economically is determined by many factors over which we have little control as individuals -even when we have formal economic freedoms and formal equality of opportunity-, whether we can obtain accurate and reliable information depends on several institutions and practices over which we, as individuals, have little control (Goldman 1999; Kitcher 2011). A complex network of social institutions, what we have called the epistemic basic structure, determines individuals' opportunities for acquiring knowledge. Accordingly, in addition to freedom of expression, the fundamental need for knowledge requires that the epistemic basic structure of societies be organized in ways that will enable people to acquire knowledge on matters that they have an interest in.

Justice in the distribution of knowledge is not a matter of people having the opportunity to acquire knowledge regarding any question to which they would like to have the answer. It is only questions that bear on individuals' plans of life and the common good that ground claims of justice. ${ }^{6}$ Even this construal of the interests that ground claims of justice in the distribution of knowledge might be too broad. For instance, a factory owner who wants to build a gadget at minimum cost has an interest in finding technologies that will decrease production costs. However, it is implausible to claim that this interest can ground a claim of justice even though such knowledge would enable the factory owner to pursue her ends more effectively. The pertinent distinction here is between knowledge as a private good and a public good. The knowledge that the factory owner is interested in is obviously a private good. The value of the knowledge she seeks is diminished when others have the same information. She is in a position to use the material resources at her disposal to pursue her interest in knowledge and be compensated, whereas someone who, for instance, wants find out about the health risks of a pollutant is not.

\footnotetext{
${ }^{6}$ It should be noted, however, that since lack of knowledge itself may prevent people from taking an active interest in some questions that bear on their life plans, questions that ground claims of justice should not be limited to those that are actual, but should also include what Goldman calls "dispositional" ones. These are questions a person would be interested if she only thought about them or knew some other facts (Goldman 1999: 95).
} 
There is another way in which not all knowledge that one has an interest in grounds claims of justice. Consider, for instance, a person's interest in knowing whether it is raining outside. Knowing this can make a difference to the success of one's short-term plans. Yet, it does not ground a claim of justice. The reason for this is that in order to know whether it is raining outside one does not need to depend on the institutional and extensive kind of social cooperation that characterizes the epistemic basic structure. One can just look outside. There is, then, a kind of division of labor implicit in our account. Certain items of knowledge don't ground claims of justice because individuals can obtain them without having to depend on the epistemic basic structures of their societies.

\section{THE EPISTEMIC BASIC STRUCTURE: INSTITUTIONS AND PROCESSES}

We propose to identify the epistemic basic structure of a society as those institutions that have the greatest impact on individuals' opportunity to obtain knowledge on questions they have an interest in through their role in the following three processes:

(a) The production of knowledge through well-conducted research carried out by institutions of science, the media, and other major sites of knowledge production;

(b) The dissemination of knowledge through the media, the Internet, the education system, libraries open to the public, and scientific publications aimed at the public;

(c) Ensuring individual capability for assimilation of knowledge through the education system, that is, providing members of the public with the critical skills and background knowledge necessary for understanding and evaluating claims that are of interest to them. ${ }^{7}$

7 The distinction we are drawing among these three processes is an analytical one. In reality, often the same institution (e.g., the university) carries out more than one of these processes at the same time, and the same activity (e.g., publishing a research article) functions both as production and dissemination. 
Justice in the distribution of knowledge, as we shall understand it then, has to do with how well and fairly these processes are carried out in a society and whether the institutions we have identified as central are carrying out their tasks properly. To determine the justness of the distribution of knowledge in a society, borrowing a spatial metaphor, we can ask how far any subject $S$ is from acquiring knowledge regarding the answers to questions that bear on the $S$ s life plans or deliberations about the common good. This depends on the following three factors:

1. Production: Is there well-conducted research about the questions that $S$ has an interest in?

2. Dissemination: If so, have the findings of this research been disseminated? Can $S$ access them? How costly is it for her to access them? Have the results of research been presented in a way that $S$ can comprehend and evaluate?

3. Ensuring individual capability for assimilation of knowledge: If $S$ can materially reach the resources, has she been provided with the requisite educational background and intellectual skills to understand and evaluate them?

This non-exhaustive list of considerations highlights how different social institutions involved in these three processes jointly contribute to an agent's acquisition of knowledge about a given question. Such considerations combine concerns of reliability and distributive justice. For instance, we can ask not only whether research on a given question, which citizens have an interest in, is being carried out, but also whether it is reliable. The same goes for its dissemination: we are not only interested in whether it is disseminated to a wide population, but also whether it is disseminated accurately, and whether it is disseminated in ways that would allow people to ascertain the reliability of what has been disseminated.

In what follows, we make a number of proposals about the proper organization of the epistemic basic structure. They naturally depend on complex empirical questions and would require further empirical research. Despite their tentative nature, we have included them for two reasons. First, they give a better sense of the policy questions that justice in the production of knowledge bears on. Second, they show that even in the absence of a canonical formulation of the principles of justice in the distribution of knowledge, we can identify ways in which the epistemic basic structure could become more just. 


\subsection{Production}

When we view the epistemic basic structure from the perspective of justice, the first question to ask is whether there is well-conducted research being done on the issues that are relevant either to the common good or to an individual's good. Well-conducted research should not be construed narrowly. Obviously, (natural and social) scientific research falls under this heading, but so does more mundane and less systematic kinds of research. Thus, well-conducted research includes, for example, investigative reporting by journalists, basic statistics and satisfaction surveys on aspects of political, economic and social life carried out by governmental and non-governmental organizations of various sorts. The reason for this broad construal is that many important life decisions depend on facts that can be obtained by relatively simple research: what is the relationship between college degrees and job opportunities in this country? What are the most paying jobs? What is the cost of living in this city? How polluted is it? What is the crime rate in its neighborhoods? How good are its public schools? etc.

Research carried out in the humanities also gives rise to claims of justice since it greatly contributes to deliberations about our own good and the common good both by systematically engaging in such deliberation and by providing us with conceptual resources to formulate our views and make sense of our experiences, ${ }^{8}$ 'enlarging our sympathies' as John Stuart Mill put it, and endowing us with the resources for greater self-understanding (Nussbaum 2010).

What are the institutional preconditions for the production of wellconducted research broadly construed? The answer naturally depends on the institution, and here we shall focus mostly (though not exclusively) on science. There are several reasons for this. First, science is arguably the most reliable institution of knowledge production in contemporary societies. Second, any well-conducted research relies on science to some degree.

${ }^{8}$ An apt example of this point can be found in Fricker's discussion of what she calls 'hermeneutical injustice'. She observes that the formulation of concepts such as post-natal depression and sexual harassment has enabled women to understand and conceptualize their experiences, and observes how the absence of these concepts 'hermeneutically' disadvantaged them. See Fricker (2007: 147-152). 
Consider other knowledge-producing institutions like the National Weather Service, the Food and Drug Administration, and the Bureau of Labor Statistics. These government agencies and offices publish, among other things, reports about the weather and the climate, safety of drugs, social policies and statistics about almost all aspects of life that are relevant to the public good and the individual's good. Even the simplest demographic statistics they publish depend on the machinery made available by the science of statistics. Likewise, reports about unemployment rates and income per capita carry epistemic weight thanks in part to the science of economics. Science -natural and social- provides the epistemic infrastructure, so to speak, that makes possible much of well-conducted research done by diverse institutions and ensures the reliability of knowledge people need in their everyday lives. Finally, science is also often directly relevant to a number of important life decisions. Should I quit smoking? Should I consume genetically modified foods? Should I believe in the existence of an intelligent creator as the best explanation of complex life forms or should I believe in the theory of evolution? Answers to such questions depend in part on some basic knowledge of medicine and biology.

Of course, ordinary citizens typically need only a small fraction of the scientific knowledge produced although they would need knowledge to identify experts and decide whom to trust. Scientific knowledge is much more needed by experts themselves who will carry out various tasks in light of it based on the division of labour that exists within their society. For instance, ordinary people do not need to have deep or extensive knowledge of medicine when they suffer from a health problem, their doctors do. Hence, an epistemic basic structure should be organized in such a way that necessary medical knowledge is produced and disseminated to the health care providers. Even then, however, we should not lose sight of the fact that the more informed a patient is about health issues the more benefit she can get from them. ${ }^{9}$

Scientific research generally produces reliable knowledge, and reliability depends not just on the right application of appropriate scientific methodology, but also on adherence to certain institutional values and norms called "the ethos of science" that includes intellectual honesty,

\footnotetext{
${ }^{9}$ Indeed, health literacy has recently become an important goal of governments. See for instance U.S. Department of Health and Human Services, Office of Disease Prevention and Health Promotion (2010).
} 
objectivity, openness, common ownership of scientific knowledge, and recognition (Resnik 1998). Distortion or fabrication of data obviously results in unreliable conclusions. Similarly, failure to eliminate biases from experimental design, data analysis and interpretation can undermine the trustworthiness of findings. Secrecy and an excessively limited intellectual commons can prevent the scientific community from confirming the published results and stall scientific progress. Finally, when recognition is displaced by commercial interests as the main motive for carrying out research, unprecedented conflicts of interest might arise that compromise objectivity.

A growing body of research suggests that the increasing commercialization of scientific research in certain disciplines (notably, biomedicine, pharmacology and genetics) has the effect of undermining the ethos of science, thereby diminishing its reliability (Bok 2003: 66-71; Krimsky 2004: 27-52; Radder 2010; Resnik 2010). A changing regime of intellectual property rights and similar legal instruments, advocated by some for incentivizing innovation and stimulating economic growth, plays a crucial role in this (Jacob 2009; Jasanoff 2005: 225-246; Mirowski 2008). What kind of a regime of intellectual property rights would best promote the growth of science and ensure its reliability and dissemination is a complicated empirical question. However, our account suggests that we need to consider their influence on people's opportunity to acquire knowledge in addition to their role in promoting or hindering economic growth and innovation. ${ }^{10}$

The production of well-conducted research raises another important issue. Given that resources are scarce, how should the priorities for research be set?

According to the current regime of science, they are determined by scientists and funding bodies (both private and public), but the interests of less privileged groups of people such as the poor and minorities tend to be neglected in research agendas. On the other hand, epistemically significant projects are sometimes pushed aside because they are perceived by an uninformed public as irrelevant to their practical needs. What is needed, therefore, is the establishment of mechanisms for democratically

\footnotetext{
${ }^{10}$ For an insightful discussion of intellectual property policies, see Fallis (2007a).
} 
determining research priorities in an informed way and identifying the primary considerations that should govern them.

There are both theoretical efforts, mainly due to Philip Kitcher, and practical efforts underway to address this need. Kitcher's particularly wellarticulated theoretical model of "well-ordered science" presents an ideal of scientific inquiry, according to which ideal deliberators representative of all viewpoints in the society determine research agendas and the allocation of resources among them through deliberative reasoning informed by experts in each field (Kitcher 2001, 2011). As for practical efforts to increase representation in science policy decision-making, several democratic countries have recently adopted a variety of mechanisms to this end: citizens' juries and panels, consensus conferences, public opinion surveys, public hearings, referenda and the like (Bucchi and Neresini 2008). In this way, public participation in science is being more actively encouraged in the hope that research will come to reflect the interests of all rather than merely those of scientists and funders.

Science of course is not the only institution that produces well-conducted research. So are, as we pointed out, investigative reporting and governmental organizations like the Bureau of Labor Statistics and the Food and Drug Administration. What are the preconditions necessary for them to produce reliable research? Given their diversity, we can't do full justice to this issue here, but we can highlight some of those preconditions. Leaving the discussion of the media for the next section, we can say that the most important institutional precondition for government agencies and offices is arguably their relative autonomy to protect them from the pressures of governments and corporations that could cause biased results. ${ }^{11}$

\subsection{Dissemination}

For the vast majority of people the media is the single most important source of information about politics, public affairs and scientific findings in general. It is therefore vital that it provides the public with accurate, unbiased, and relevant information. By informing the public about how

${ }^{11}$ For the need to make the FDA independent from the corporate pressures see Angell (2005: 208-214 and 242-243). 
their government is performing, by providing a venue for raising various concerns and deliberating about different policies, and by acting as an intermediary between research findings and the general public, the media can contribute significantly to the political, intellectual and daily life of a society.

A quick review of the current state of the media in some countries, for example in the United States, can point to some of the most important measures that need to be taken for a more just epistemic basic structure. The mass media in the United States is a commercial enterprise whose major source of revenue is advertisement. For that reason the interests of the advertisers influence the form and content of what is reported and who the media targets as their audience. Most of the newspapers, magazines, book publishers, and radio and television stations are owned by a handful of global-dimension firms as a result of the Telecommunications Act of 1996 (Bagdikian 2004: 3). Furthermore, due in large part to the media conglomerates' profit-driven strategies, journalism suffers from significant budget cuts, fewer staff, and a general atmosphere of job insecurity, all of which have contributed to the relaxation of professional news standards, the virtual disappearance of investigative journalism, and the increasing coverage of trivia and entertainment at the expense of serious news (Goldman 1999: 182-188; McChesney 2008: 415-419).

Accordingly, the availability of sufficient resources for investigative reporting, and legislation that would promote media diversity can drastically improve justice in the dissemination of knowledge. Similarly, certain changes in the norms of reporting can also contribute to a better understanding of public issues including scientific ones, some of which have a direct bearing on people's political choices. Consider, for instance, humaninduced global warming. Proponents of climate denialism have benefited greatly from the reporting conventions of the mainstream media that seek "balance" in the form of giving equal time to climate scientists and denialists (Jacques et al. 2008: 255; Oreskes and Conway 2011: 349-385). A more nuanced understanding of what objective reporting requires would do a much better job of informing the public about global warming.

Information technology is increasingly becoming an indispensable tool for communication and for the acquisition of all kinds of knowledge that people have an interest in, which in turn empowers them economically (e.g., by finding out about available jobs) as well as politically (e.g., by finding out 
about the views of political actors) (Fallis 2007b). In line with this, the United Nations has suggested, and a number of countries including France, Finland, and Estonia have recognized, access to the Internet as a right (Lucchi 2011: 676; Mathiesen 2012). Indeed, as Mathiesen argued, the right to the Internet can be seen as a 'linchpin right' since it facilitates the exercise of other human rights. Its satisfaction involves providing and maintaining a 'critical infrastructure' (such as servers and transmission lines) and also removing bureaucratic and financial barriers to access (Mathiesen 2012). The removal of financial barriers will of course depend on the economic resources of a society. A radical solution is to make access to the Internet free for all. A more realistic solution is to make it affordable for most people. For those who cannot afford it, free Internet services might be established in public libraries in economically disadvantaged neighborhoods (Fallis 2007b: 38).

The dissemination of scientific knowledge raises issues of its own. Cuttingedge research is primarily of value to researchers themselves, and many contemporary societies provide their researchers access to it through their institutions. Despite this, commercialization of science can and does limit dissemination of scientific research in certain disciplines, a phenomenon known as 'trade secrecy', and consequently prevents researchers from confirming the accuracy of published results (Krimsky 2004: 82-85). This problem provides further support for our earlier suggestion that the negative influence of commercial interests on science should be mitigated.

Even though scientific research is primarily of value to scientists, ordinary citizens will need to know some of it as well. Naturally, most research will be difficult for laypeople to comprehend and evaluate even when it is directly relevant to their important life decisions. Therefore, a just epistemic basic structure requires measures that will present the findings of scientific research relevant to their interests in ways that will be accessible to them.

High-quality science journalism freed from the pressures of commercial and sensational publishing and guided by a public purpose is one measure that can increase both the accessibility of scientific research and its responsible reporting. ${ }^{12}$ Similarly, giving scientists incentives to write popular science

\footnotetext{
${ }^{12}$ The MMR vaccine-autism controversy in England in late 1990s and early 2000s is one of the many cases where sensationalist reporting has done serious damage, see Goldacre (2008: 273-314).
} 
books and articles on issues of general interest would serve the same purpose (Mooney and Kirshenbaum 2009). The policy of including lay abstracts of all scientific articles, a practice adopted by some medical journals, would be another measure. Finally, statements issued by scientific bodies indicating both the existing current scientific consensus and the problematic issues where a consensus is lacking can also be a useful source of information for all.

Citizens will often need to be able to determine who has the relevant information to pursue their interests and which experts to trust. This they can do by asking questions like the following (Anderson 2011: 145-149; Goldman 2001): To which research institution does the putative expert belong and what are her credentials? Have her claims been subjected to peer review? What were the sources of funding for her research? Did she have any conflicts of interests? A just epistemic basic structure should make the information, which would enable people to answer these questions, easily available. Indeed, a number of scientific (especially medical) journals now routinely provide this sort of information for their readers and others can follow suit. The media too, when presenting the views of experts, could adopt a similar practice and even offer a careful summary of past debates that they have been a part of, the objections that have been raised to their claims and their responses. ${ }^{13}$

\subsection{Ensuring individual capability for assimilation of knowledge}

Even if the institutions dealing with the production and dissemination of knowledge are in order, members of society can fail to benefit from the knowledge these institutions provide when they lack the necessary intellectual skills and background knowledge. For this reason, justice in the distribution of knowledge requires that people be provided with an education equipping them with (a) scientific literacy, which includes knowledge of basic scientific facts and a general understanding of scientific methods; (b) numerical literacy, which also includes an understanding of the

\footnotetext{
13 Since our proposal requires institutions making some facts about themselves public, it entails redrawing the boundary between what is properly considered public and private knowledge. However, given the public nature of these institutions and the public interest at stake, such redrawing of the boundary seems justified.
} 
basic concepts of statistics since much of the information that bears on social and political issues relies on statistical data; (c) critical reasoning skills that enable citizens to evaluate arguments offered to them; (d) computer literacy, since computers and the Internet are the main sources for acquiring knowledge in contemporary societies; and (e) some knowledge of the cognitive biases to which human beings are prone so that they will be able, in some cases, to avoid them and, in others, be more receptive to scientific findings that clash with their intuitive judgments. This is not an unachievable ideal. A good basic education can provide all or almost all of the skills and knowledge in question.

\section{PRINCIPLES OF JUSTICE IN THE DISTRIBUTION OF KNOWLEDGE}

We have not attempted to provide a canonical formulation stating the necessary and sufficient conditions for the existence of justice in the distribution of knowledge, or, to put it differently, for when the distribution of opportunity for acquiring knowledge is just. We doubt that such a formulation is possible. Individuating facts or beliefs about facts is next to impossible. Moreover, beliefs are interrelated, and the revision of one belief may result in further revisions. Both of these points make comparison of how two individuals fare epistemically difficult. ${ }^{14}$

Our proposals are not, in the first instance, concerned with bringing about a specific distribution of opportunity for acquiring knowledge within a society. Rather, we are concerned with how the epistemic basic structure of a society is organized and whether it serves the needs of people. As our discussion in the previous section demonstrates, substantive proposals can still be made without a fully worked out set of principles for the distribution of knowledge.

Two further clarifications are in order. First, measures required to promote

\footnotetext{
${ }^{14}$ For an excellent discussion of these difficulties see Treanor (2013). Treanor also makes a positive proposal about how to unpack our ordinal judgements regarding knowing more or less in terms of our representations of the world being more or less similar to the way the world is. However, as he notes, his proposal also does not produce a quantifiable measure (Treanor 2013: 596-7).
} 
justice in the distribution of knowledge are not only compatible with, but also require, in some cases, maintaining autonomous institutions. It would also be a mistake to assume that all requirements of justice in the distribution of knowledge are to be enforced by law. Some of these requirements are norms that should be adhered to by members of the relevant bodies but not legally enforced, and it is possible to criticize existing norms in light of the harm they do to the opportunities of people for acquiring knowledge. So, for example, when we object to climate denialists being given equal time for the sake of objectivity, we are not suggesting that they should be censored, but only that the media should work with a more nuanced understanding of what objectivity requires of their reporting.

Similarly, we are not in favor of tight controls over the media. Our argument isn't that freedom of expression should be limited, but that it should be supplemented with certain institutional measures and norms that will enable people to acquire the knowledge they have an interest in. We are not suggesting that the state should always intervene directly with the institutions that make up the epistemic basic structure. Rather, it can improve their functioning by ensuring certain background conditions such as preventing monopolies in media ownership.

Second, on our account, justice in the distribution of knowledge requires that people have the opportunity to obtain knowledge on questions they have an interest in. It does not put forth a perfectionist and unattainable ideal of each individual becoming an expert on every topic. It requires only that when they are curious about a question they have an interest in, they should have the means to obtain knowledge about it.

\section{JUSTICE IN THE DISTRIBUTION OF KNOWLEDGE AND RAWLS'S THEORY OF JUSTICE}

We have argued that the basic interest in knowledge, which also underwrites freedom of expression, can be satisfactorily served only when the epistemic basic structure of a society is organized with a view to ensuring justice in the distribution of knowledge by providing everyone with the opportunity to acquire knowledge on matters they have an interest in. In this section, we illustrate how the framework we have developed in this paper can be incorporated into Rawls's theory of justice. 
Rawls's theory of justice deals with the distribution of what he calls primary goods (basic rights and liberties, freedom of movement, and free choice among a wide range of occupations, income and wealth, the powers of offices and positions of responsibility, and the social bases of self-respect) (Rawls 2001: 58-9). These are goods necessary for the development and exercise of the two moral powers: the capacity for a sense of justice - "the capacity to understand, to apply, and to act from the public conception of justice which characterizes the fair terms of social cooperation" - and the capacity for a conception of the good - "the capacity to form, to revise, and rationally to pursue a conception of one's rational advantage or good" (Rawls 1996: 19). According to Rawls's first principle of justice, "each person has an equal claim to a fully adequate scheme of equal basic rights and liberties", where basic liberties include freedom of expression and political liberties (Rawls 1996: 5).

Rawls's theory of justice gives a prominent place to freedom of expression because it is essential for the adequate development and exercise of the two moral powers. Freedom of expression contributes to the exercise and development of our sense of justice by enabling us to take part in the political process and deliberate about the common good. It contributes to the exercise and development of a capacity for a conception of the good by enabling us to reason about different conceptions of the good. These arguments for taking freedom of expression to be a primary good also apply to knowledge. Knowledge can be considered a primary good because of the role it plays in people's deliberations about their own good and the common good, that is, its role in the exercise and development of their capacity for a conception of the good and their capacity for a sense of justice respectively.

Even though it is not treated at length, people's interest in knowledge is acknowledged by Rawls in his discussion of the requirements of his principles of justice. When speaking of basic liberties and their priority, Rawls maintains that they "are to guarantee equally for all citizens the social conditions essential for the adequate development and the full and informed exercise of their two moral powers" (Rawls 2001: 112, emphasis added). When discussing the equal worth of political liberties he requires he writes,

All citizens should have the means to be informed about political issues. They should be in a position to assess how proposals affect their well-being and which policies advance their conception of the public good (Rawls 1999: 198). 
One characteristic of a well-ordered society, according to Rawls, is publicity, which entails that citizens affirm his principles of justice, know that the basic structure of their society satisfies these principles and recognize the general facts in light of which parties in the original position choose principles of justice (Rawls 2001: 121). These facts include "the methods and conclusions of science when not controversial" (Rawls 2001: 90). This indicates that Rawls assumes citizens in a society that is just by his standards having access to a significant body of knowledge.

Moreover, when discussing fair equality of opportunity, Rawls does not limit the scope of opportunity to positions. He suggests that people who are equally talented and motivated should have "equal prospects of culture and achievement" and emphasizes the importance of education "in enabling a person to enjoy the culture of his society and take part in its affairs" (Rawls 1999: 639, emphasis added). Therefore, the concern with a just epistemic basic structure is one that Rawls's theory of justice can take on board and can be said to implicitly assume.

Indeed, some commentators have argued that Rawls should treat "access to information" as a primary good (van den Hoven and Rooksby 2008). However, from our perspective van den Hoven and Rooksby's account has serious shortcomings because the idea of an epistemic basic structure is absent from their framework. They are concerned only with "access to an informative object such that that access would be sufficient to produce knowledge" (van den Hoven and Rooksby 2008: 381, emphasis in the original). ${ }^{15}$ Ensuring this, they suggest, "may involve distribution of information-bearing objects, or ensuring that individuals have ready access to such objects" (van den Hoven and Rooksby 2008: 381). Thus, they are concerned with only a subpart of what we have discussed under dissemination of knowledge. The production of knowledge itself, the reliability and fairness in the dissemination of knowledge - except for people having access to sources of information- and making sure that people have the capability to assimilate the knowledge that has been disseminated is absent from their account. A society in which people have access to information in the way van den Hoven and Rooksby conceive of it can fail to provide its members with the opportunity to acquire knowledge because they lack the necessary intellectual skills or because the knowledge they need

${ }^{15}$ Fallis (2007b) also suggests that knowledge is a primary good, but does not develeop the idea. 
is not produced at all.

The fact that people's opportunity to acquire knowledge depends on the workings of the epistemic basic structure of their societies also explains why a Rawlsian society would need to address its organization. It is likely that a society that realizes Rawls's two principles of justice can be expected to do better than contemporary societies with respect to justice in the distribution of knowledge since people who have their fair share of economic resources and freedom of expression will have more opportunities for obtaining knowledge on matters they have an interest in. However, the fact that people will do better within a given epistemic basic structure is not the same as there being a well-functioning and fair epistemic basic structure. A Rawlsian society will have to take measures so that its epistemic basic structure is functioning well enough to address justice in the distribution of knowledge, that is, its knowledge producing and disseminating systems such as science, media, the Internet, various governmental agencies and offices are all functioning properly. A Rawlsian society can incorporate many of the measures we have suggested as means of realizing the equal worth of political liberties and ensuring fair equality of opportunity, and it may, more directly, treat the opportunity to acquire knowledge as a primary good. None of the measures we have proposed will require major revisions to Rawls's theory, but they will mean that Rawlsians should treat the epistemic basic structure of a society as falling under the purview of justice -an issue which has been neglected in discussions of Rawls' theory.

No doubt, justice in the distribution of knowledge is only one consideration of justice among others, and its promotion may be rightly limited when it conflicts with certain freedoms and other requirements of justice. Moreover, ensuring a just distribution of knowledge may not be the only thing people demand from the epistemic basic structure of their societies. They may want it to contribute, for example, to economic growth by fostering innovation. Accordingly, the way the epistemic basic structure of a society would need to be organized if our only concern were with justice in the distribution of knowledge and how it ought to be organized when other aspects of justice are also taken into account need not be the same. A full treatment of the relationship between the epistemic and other components of justice, which would identify the relevant tradeoffs and how they should be settled, 
requires further research. ${ }^{16}$

\section{CONCLUDING REMARKS}

Despite the fact that knowledge is a good no less important than standard goods like income, wealth, liberties and opportunities, existing theories of justice do not consider its distribution to be a matter of justice. The purpose of this article has been to show that the distribution of knowledge deserves to be treated as a matter of justice in its own right. Like most goods, knowledge too can be produced, disseminated, obtained and enjoyed, and the function of what we have called the epistemic basic structure of a society is to ensure precisely that. Systematic deprivation of the opportunity to acquire knowledge as a result of an unfairly organized and/or poorly functioning epistemic basic structure constitutes an injustice no less serious than income- or liberty-deprivation. Injustice in the distribution of knowledge also facilitates other injustices such as inequalities in healthcare, a distorted political process, not to mention ineffective and unjust legislation. It is also a precondition for the effective exercise of many rights that people have.

In this article, we have focused on institutions that make up the epistemic basic structure of society and not addressed individual epistemic norms. This is not because individual epistemic norms do not influence individuals' opportunity to acquire knowledge -they certainly do. However, we think that the study of the norms required to ensure equality of opportunity to acquire knowledge are better worked out with an institutional framework in place. The same set of individual epistemic norms can have significantly different effects when the background insittutions are different. Moreover, the instituitional background can influence the norms that individuals adhere to as the erosion of the ethos of science under increasing commercialization indicates. We are also not suggesting that the only considerations of justice that bear on the epistemic basic structure and individual epistemic norms are ones that influence people's opportunity to acquire knowledge. For instance, as Miranda Fricker has shown in her pioneering work, there is an epistemic injustice 'when prejudice causes a

\footnotetext{
${ }^{16}$ We owe this point to an anonymous referee.
} 
hearer to give a deflated level of credibility to a speaker's word', because it denies them the status of a giver of knowledge and a being possessing reason (Fricker 2007: 1, 44). ${ }^{17}$ By pointing to the myriad ways our epistemic lives depend on social processes, social epistemologists have made it possible to ask how considerations of justice bear on epistemic practices and institutions. The considerations we discussed in this paper are one such set of considerations but certainly not the only one.

Extending the scope of justice to include knowledge and the epistemic basic structure, we believe, not only fills a lacuna in contemporary theories of justice, but also provides us with a powerful discourse for underlining and addressing certain kinds of injustices that might be downplayed or outright ignored. Our account of justice in the distribution of knowledge has also the advantage of treating diverse social institutions such as science, media, schools, certain government offices as well as political concerns about democratic self-rule and just legislation from the same perspective within a unifying normative theoretical framework. Such a framework, we hope, can contribute to the articulation of demands such as the right to Internet access, increased transparency in scientific research, greater public understanding of science, a press that can function as a fourth estate, and (continued) public funding of universities and at the same time identify a normative commitment shared by them.

ACKNOWLEDGEMENTS: We thank Ateş Altınordu, Ayşen Candaş, Philip Kitcher, Nicholas Vrousalis, two anonymous referees and an associate editor of Episteme for their extensive comments. An earlier version of this paper was presented at Koç and Boğaziçi universities. We are grateful to audiences there for their comments. Kurtulmuş would like to acknowledge the financial support of the Scientific and Technological Research Council of Turkey (TUBITAK Career Development Grant No. 112K412).

\footnotetext{
${ }^{17}$ Interestingly, the issue of justice in the distribution of knowledge with which our article is concerned is one that Fricker raises at the beginning of her book, but dismisses (Fricker 2007: 1).
} 


\section{References}

Anderson, E. 2011. 'Democracy, Public Policy, and Lay Assessments of Scientific Testimony.' Episteme, 8: 144-164.

Angell, M. 2005. The Truth about the Drug Companies. New York: Random House.

Bagdikian, B. 2004. The New Media Monopoly. Boston: Beacon Press.

Bok, D. 2003. Universities in the Marketplace. Princeton: Princeton University Press.

Bucchi, M. and Neresini, F. 2008. 'Science and Public Participation.' In E. J. Hackett, O. Amsterdamska, M. Lynch, and J. Wajcman (eds), The Handbook of Science and Technology Studies, $3^{\text {rd }}$ edition, pp. 449-472. Cambridge, MA: MIT Press.

Cohen, J. 1993. 'Freedom of Expression.' Philosophy E̋ Public Affairs, 22: 207-263.

Fallis, D. 2007a. 'Toward an Epistemology of Intellectual Property.' Journal of Information Ethics, 16: 34-51.

. 2007b. 'Epistemic Value Theory and the Digital Divide.' In E.

Rooksby and J. Weckert (eds), Information Technology and Social Justice, pp. 29- 46. Hershey, PA: Information Science Publishing.

Finnis, J. 2011. Natural Law $\mathcal{E}^{\circ}$ Natural Rights, $2^{\text {nd }}$ edition. Oxford: Oxford University Press.

Fricker, M. 2007. Epistemic Justice: Power and the Ethics of Knowing. Oxford: Oxford University Press.

Goldacre, B. 2008. Bad Science. London: Fourth Estate.

Goldman, A. I. 1999. Knowledge in a Social World. Oxford: Oxford University Press.

. 2001. 'Experts: Which Ones Should You Trust?' Philosophy and Phenomenological Research, 63: 85-110. 
Hotez, P. 2009. 'Neglected Diseases Amid Wealth in The United States and Europe'. Health Affairs, 29: 1720-1725.

Jacob, M. 2009. 'On Commodification and the Governance of Academic

Research'. Minerva, 47: 392-405.

Jacques, P. J., Dunlap, R. E. and Freeman M. 2008. 'The Organisation of Denial: Conservative Think Tanks and Environmental Skepticism.' Environmental Politics, 17: 349-385.

Jasanoff, S. 2005. Designs On Nature. Princeton: Princeton University Press.

Kitcher, P. 2001. Science, Truth, and Democracy. Oxford: Oxford University Press. . 2011. Science in a Democratic Society. Amherst: Prometheus Books.

Krimsky, S. 2004. Science in the Private Interest. Lanham: Rowman and Littlefield.

Kymlicka, W. 1989. 'Liberal Individualism and Liberal Neutrality.' Ethics, 99: 883-905.

Lucchi, N. 2011. 'Access to Network Services and Protection of Constitutional Rights: Recognizing the Essential Role of Internet Access for the Freedom of Expression.' Cardozo Journal of International and Comparative Law, 19: 645-678.

Mathiesen, K. 2012. 'The Human Right to Internet Access: A Philosophical Defense.' International Review of Information Ethics, 18: 9-22.

McChesney, R.W. 2008. The Political Economy of Media. New York: Monthly Review Press.

Meiklejohn, A. 1948. Free Speech and Its Relation to Self-Government. NewYork: Harper \& Brothers.

Mettler, S. 2010. 'Reconstituting the Submerged State: The Challenges of Social Policy Reform in the Obama Era.' Perspectives on Politics, 8: 803-824. 
Mill, J. S. 1989. On Liberty and Other Writings. Cambridge: Cambridge University Press.

Mirowski, P. 2008. 'Livin' with the MTA.' Minerva, 46: 317-342.

Mooney, C. and Kirshenbaum, S. 2009. Unscientific America: How Scientific Illiteracy Threatens Our Future. New York: Basic Books.

National Research Council. 2010. Advancing the Science of Climate Change. Washington, DC: National Academies Press.

Norton, M. I. and Ariely, D. 2011. 'Building a Better America-One Wealth Quintile at a Time.' Perspectives on Psychological Science, 6: 9-12.

Nussbaum, M. C. 2010. Not for Profit: Why Democracy Needs the Humanities. Princeton: Princeton University Press.

Oreskes, N. and Conway, E. M. 2011. Merchants of Doubt: How a Handful of Scientists Obscured the Truth on Issues from Tobacco Smoke to Global Warming. London: Bloomsbury.

Pew Research Center for the People and the Press. 2010. Little Change in Opinions About Global Warming. http://www.peoplepress.org/files/legacy-pdf/669.pdf. Accessed October 28, 2013.

Radder, H. 2010. 'Mertonian values, scientific norms, and the commodification of academic research.' In H. Radder (ed), The Commodification of Academic Research, pp. 231-258. Pittsburgh: University of Pittsburgh Press.

Rawls, J. 1996. Political Liberalism, paperback edition. New York: Columbia University Press. . 1999. A Theory of Justice, rev. ed. Oxford: Oxford University Press. . 2001. Justice as Fairness: A Restatement. Cambridge MA: Harvard University Press.

Resnik, D. 1998. The Ethics of Science: An Introduction. London: Routledge. . 2010. 'Financial Interests and the Norms of Academic Science.' In 
H. Radder (ed), The Commodification of Academic Research, pp. 65-89. Pittsburgh: University of Pittsburgh Press.

Treanor, N. 2013. 'The Measure of Knowledge.' Noûs, 47: 577-601.

U.S. Department of Health and Human Services, Office of Disease Prevention and Health Promotion 2010 National Action Plan to Improve Health Literacy. Washington DC: U.S. Department of Health and Human Services.

http://www.health.gov/communication/hlactionplan/pdf/Health_Literacy_ Action_Plan.pdf. Accessed on 22 January 2015.

van den Hoven, J. and Rooksby E. 2008. 'Distributive Justice and the Value of Information: A (Broadly) Rawlsian Approach.' In J. van den Hoven and J. Weckert (eds), Information Technology and Moral Philosophy, pp. 376-396. New York: Cambridge University Press.

Waring, M. 1988. If Women Counted: A New Feminist Economics. San Francisco: Harper \& Row. 